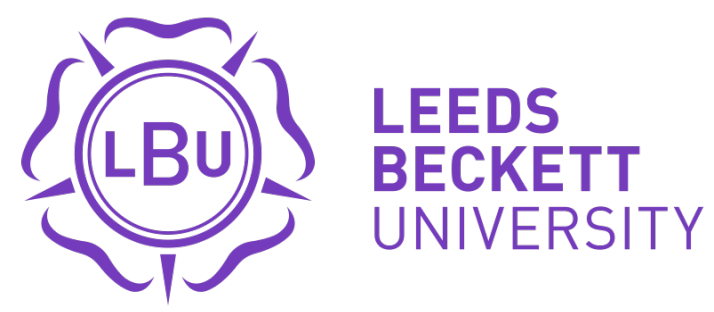

Citation:

Boyda, D and McFeeters, D and Dhingra, $K$ and Rhoden, $L$ (2018) Childhood maltreatment and psychotic experiences: exploring the specificity of early maladaptive schemas. Journal of Clinical Psychology. ISSN 0021-9762 DOI: https://doi.org/10.1002/jclp.22690

Link to Leeds Beckett Repository record:

https://eprints.leedsbeckett.ac.uk/id/eprint/5143/

Document Version:

Article (Accepted Version)

The aim of the Leeds Beckett Repository is to provide open access to our research, as required by funder policies and permitted by publishers and copyright law.

The Leeds Beckett repository holds a wide range of publications, each of which has been checked for copyright and the relevant embargo period has been applied by the Research Services team.

We operate on a standard take-down policy. If you are the author or publisher of an output and you would like it removed from the repository, please contact us and we will investigate on a case-by-case basis.

Each thesis in the repository has been cleared where necessary by the author for third party copyright. If you would like a thesis to be removed from the repository or believe there is an issue with copyright, please contact us on openaccess@leedsbeckett.ac.uk and we will investigate on a case-by-case basis. 
Running head: Child maltreatment and psychotic experiences

Running head: Child maltreatment and psychotic experiences

\section{Childhood maltreatment and psychotic experiences: exploring the specificity of early maladaptive schemas.}

Dr David Boyda ${ }^{1}$, Dr Danielle McFeeters ${ }^{1}$, Dr Katie Dhingra ${ }^{2}$ and Ms Laura Rhoden ${ }^{1}$

${ }^{1}$ Faculty of Education Health and Wellbeing, University of Wolverhampton

${ }^{2}$ School Of Social Sciences, Leeds Beckett University Word count (exc. figures/tables): 4080

${ }^{*}$ Requests for reprints should be addressed to Dr David Boyda, University of Wolverhampton, West Midlands, WV1 1LY, UK (e-mail: D.Boyda@wlv.ac.uk) 


\begin{abstract}
Objective: One potential mechanism that has received limited attention within psychosis research, is early maladaptive schemas (EMS). Our aim was to examine if EMS acts as a potential mediating pathway between early trauma and psychotic symptomology.
\end{abstract} Methods: A quantitative survey was hosted online. $\mathrm{N}=302$ participants took part. The analysis employed a multiple mediation framework. Results: Analysis demonstrated significant specificity effects. Different forms of child maltreatment were significantly associated with psychosis experiences through specific dimensions of maladaptive schemas. Conclusions: Results indicated specificity effects in that specific types of maltreatment are associated with specific maladaptive schemas. From a practitioner's perspective, these findings offer credence to cognitive theories of psychopathology, and support the validity of EMS identification and modification among clients with psychotic symptomology; both as a fundamental component of traditional CBT and within specialised schema focused therapy. 


\section{Introduction}

Experiences of child maltreatment rarely occur in isolation; children who are exposed to one type of maltreatment (e.g. neglect, physical, sexual and emotional abuse etc.) are often exposed to other types (Christoffersen, Armour, Lasgaard, Andersen, \& Elklit, 2013; Gilbert et al., 2009). Such experiences, whether by commission (i.e., abuse) or omission (i.e., neglect) by the child's caregiver, are associated with a range of internalising and externalising psychopathology including anxiety, depression, antisocial behaviour, and substance-use disorder (Abajobir et al., 2017; Banyard, Williams, \& Siegel, 2001; Dias, Sales, Mooren, Mota-Cardoso, \& Kleber, 2017; Manly, Cicchetti, \& Barnett, 1994; Molendijk, Hoek, Brewerton, \& Elzinga, 2017).

A growing number of studies indicate that childhood maltreatment may also be a risk factor for schizophrenia and other psychotic disorders (Cutajar et al., 2010; McGrath et al., 2017; Mørkved et al., 2017). Recent meta-analyses by Varese et al. (2012) and Bonoldi et al. (2013) show a higher prevalence of child maltreatment among individuals diagnosed with a psychotic disorder, than within samples taken from the general population. Likewise, childhood maltreatment may also create a vulnerability to low-level psychotic experiences (PE), i.e. in the absence of a clinical disorder (Bhavsar et al., 2017; Boyda \& McFeeters, 2015; Sommer et al., 2010). Research shows such experiences are transitory in about $80 \%$ of individuals, around $20 \%$ go on to develop persistent psychotic experiences and $7 \%$ a psychotic disorder, with an annual transition rate below 1\% (Kaymaz et al., 2012; Linscott \& van Os, 2013; Zammit et al., 2013).

In other words, an "extended phenotype" or "continuum" may exist between lowlevel psychotic experiences and more clinically relevant disorders, thus may share many of the same demographic, etiological, familial, and psychopathological correlates (Reininghaus, 
Priebe, \& Bentall, 2012; van Os \& Linscott, 2012). This continuity implies that, at all phenomenological and temporal stages of the "extended psychosis phenotype", individuals may become help-seeking and classified as meeting criteria for an ultrahigh-risk (UHR) state (van Os \& Linscott, 2012). That said, whilst research has consistently identified a relationship between child maltreatment and psychosis symptomology, little is known about the psychological mechanisms that may underpin this association.

One potential mechanism that has received limited attention within psychosis research is the role of early maladaptive schemas (EMS; Young, Klosko, \& Weishaar, 2003). EMS are multidimensional and encapsulate cognitions, emotions, and bodily sensations. They can be described as broad, self-perpetuating, maladaptive life themes which originate from repetitive relational experiences, and unmet psychological needs with significant others in childhood and adolescence (Young et al., 2003). As lifespan development takes place, EMS become 'trait-like' due to the presence of strong emotions and evolve into component parts of the self and others. Once formed, these structures are the lenses by which we view the world and help us to interpret every stimulus as well as maintaining cognitive consistency (Rafaeli, Bernstein, \& Young, 2010). EMS are thought to represent the deepest level of impaired thinking, and when triggered, will dominate thoughts and feelings, leading to negative emotions, and dysfunctional cognitions (Young et al., 2003b).

Adverse childhood events can lead to the manifestation of negative schemas regarding the self, which in turn may alter the ways in which an individual evaluates his or herself and others. This can foster cognitions of vulnerability, and humiliation which have not only been associated with a predisposition to hallucinations and delusions, but also the likely coexpression of other psychiatric problems (Garety, Kuipers, Fowler, Freeman, \& Bebbington, 2001; Kraan et al., 2017). As such, EMS reflect early adverse interaction patterns and have been associated with a broad range of psychiatric illnesses including anxiety and depression 
(Cormier, Jourda, Laros, Walburg, \& Callahan, 2011; Hawke \& Provencher, 2011), suicidal behaviours (Dutra, Callahan, Forman, Mendelsohn, \& Herman, 2008; Flink et al., 2017), personality disorders, psychotic symptomology (Bortolon, Capdevielle, Boulenger, GelyNargeot, \& Raffard, 2013) as well as relational and interpersonal difficulties (Thimm, 2013). Consequently, EMS may prove to be a useful construct through which to examine how delusional and hallucinatory content may manifest. However, despite a theoretically proposed close connections between EMS and Axis I disorders, to the authors' best knowledge, only a small number of studies have examined EMS in relation to psychosis (Bortolon et al., 2013; Sundag, Ascone, de Matos Marques, Moritz, \& Lincoln, 2016; Taylor \& Harper, 2016) and no study to date has yet investigated if specific EMS uniquely mediate the trauma-psychosis relationship.

This nature of this study is exploratory, however, given that psychotic-experiences in epidemiological non-help-seeking samples index psychometric risk for psychotic disorder (van Os et al., 2012a), the present study aims to extend the trauma-psychosis literature by addressing several objectives. The first objective is to identify the comparative impact of different forms of child maltreatment (e.g., sexual abuse, neglect, witnessing IPV etc.) on EMS in a general population sample. The second objective is to examine the relationship between EMS and psychotic experiences. The final objective is to examine the mediating role of EMS domains (defectiveness, dependency, enmeshment, and emotional inhibition) in the relationship between child maltreatment and psychotic experiences. 


\section{Method and materials}

Participants and sampling strategy

A general population sample was obtained through advertisement on various social media forums. A brief study description was provided alongside the distributing collector link which navigated participants to the online survey resulting in a total sample of 302 participants."

\section{Covariates}

\section{Demographics}

Information was requested in relation to participant's age, gender, the area of residence (Rural/Urban), ethnicity and familial occupational classification. Ethnic categories were based upon the census classification for England. Due to the lack of ethnic diversity in the sample, the variable was recoded as $0=$ "Other ethnic group" and $1=$ "White".

\section{Socio-economic status}

A proxy measure of socio-economic status was derived from the question "Which of the following best represents the occupational category of your household?" Responses were based on the 9 major groups of the standard occupational classification (Office of National Statistics, 2015). An additional unemployed/retired/homemaker category was included. Higher scores coincide with greater qualifications; training and experience thus are broadly representative of higher SES.

\section{Substance use}

Participants were also asked three questions regarding the frequency with which they consumed Class A, B or C drugs. Responses ranged from $0=$ "Never" to $4=$ " A lot". 


\section{Measures}

Variables indexing early negative life experiences were derived from the Adverse Childhood Experiences questionnaire (ACE-IQ; Adverse Childhood Experiences International Questionnaire, 2008). Research evidence has demonstrated the ACE is a reliable, valid and economic screen for the retrospective assessment of adverse childhood experiences in in clinical and non-clinical samples (Galletly, Van Hooff, \& McFarlane, 2011; Vallejos, Cesoni, Farinola, Bertone, \& Prokopez, 2017; Whitfield, Dube, Felitti, \& Anda, 2005; Wingenfeld et al., 2011).

\section{Relationship with parents}

Two questions were extracted from the relationship with parent's/guardian's section of the questionnaire: "Did your parents/guardian's (1) understand your problems and worries", (2) really know what you were doing with your free time when you were not at school or work". These were scored on a 5-point Likert scale ranging from $0=$ "Always" to $4=$ "Never". A total score was computed with higher scores indicative of a poorer parent-child relationship.

\section{Witness to violence in the home}

Exposure to violence in the home was generated from three items: "In the first 18 years of your life did you ever see or hear a parent or household member in your home (1) being yelled at, screamed at, sworn at, insulted or humiliated, (2) being slapped, kicked, punched or beaten up, (3) being hit, cut with an object, such as a stick (or cane), bottle, club, knife, whip etc." Responses were scored on a 4-point Likert scale ranging from $0=$ "Never" to $3=$ "Many times". A composite score was computed with higher scores representing more frequent exposure. 


\section{Emotional abuse}

A measure of emotional abuse was derived from responses to the item: "During the first 18 years of your life did a parent, guardian or other household member yell, scream or swear at you, insult or humiliate you?" Responses were scored on a 4-point Likert scale ranging from $0=$ "Never" to 3= "Many times".

\section{Physical Abuse}

Experiences of physical abuse by a parent or caregiver was formed from two items: "During the first 18 years of your life did a parent, guardian or other household member (1) spank, slap, kick, punch or beat you up, (2) hit or cut you with an object such as a stick (or cane), bottle, club, knife, whip etc." Items were scored on a 4-point Likert scale ranging from $0=$ "Never" to 3= "Many times". A total score was computed with higher scores indicative of a greater frequency of physical abuse before the age of 18 .

\section{Childhood neglect}

Childhood neglect was derived from the items: "During the first 18 years of your life, did a parent, guardian or other household member (1) threaten to or actually abandon you or throw you out of the house, (2) not give you enough food when they could easily have done so?" Responses were scored on a 4-point Likert scale ranging from $0=$ "Never" to 3= "Many times". A total score was computed with higher scores indicating more frequent occurrences of neglect.

\section{Family environment}

Three items from the family environment section of the ACE-IQ "Did you live with a household member who was... (1) a problem drinker or alcoholic, misused street or prescription drugs, (2) depressed, mentally ill or suicidal, (3) ever sent to jail or prison?" were 
selected and combined to form a dose-response variable, (scored $\mathrm{No} / \mathrm{Yes}$ ) and ranged from 0 to 3. A higher number of events equated to a more dysfunctional family environment.

\section{Childhood sexual abuse}

Childhood sexual abuse was created from four items "In the first 18 years of your life did someone (1) touch or fondle you in a sexual way when you did not want them to, (2) make you touch their body in a sexual way when you did not want them to, (3) attempt oral, anal or vaginal intercourse with you when you did not want them to (4) actually have oral, anal or vaginal intercourse with you when you did not want them to". These were combined to compute a dose-response variable (scored $\mathrm{No} / \mathrm{Yes}$ ) and ranged from 0 to 4 with higher scores signifying more childhood sexual abuse experiences.

\section{Early Maladaptive Schema (EMS)}

EMS items were extracted from the 75 item Young's Schema Questionnaire-Short Version (YSQ-SF; Young et al., 2003c). The YSQ-SF assesses the presence of 15 EMS (5 items per scale) relating to an individuals' cognitions surrounding the self, other people and the world. Participants are asked to rate the extent to which each item applies to them on a 6-point Likert scale ranging from $1=$ "Not at all" to 6= "Exactly". A total score on each subscale is computed and then averaged with mean scores of $2>$ considered to be indicative of the presence of a clinically relevant EMS (Sundag et al., 2016). Four of the fifteen EMS subscales were selected based on conceptual and theoretical evidence (emotional inhibition, defectiveness, dependency and enmeshment). Emotional inhibition has been found to mediate the relationship between childhood maltreatment and psychological distress (Krause, Mendelson, \& Lynch, 2003), whereas defectiveness/shame has been shown to be elevated amongst adults with schizophrenia compared to adults without (Bortolon et al., 2013). 
Research evidence also suggests enmeshment may be psychosis-specific and help to differentiate individuals with psychosis from other forms of psychopathology such as depression (Sundag et al., 2016b). Furthermore, dependency and enmeshment components have been found to be more strongly linked with psychosis related distress than other subscales (Taylor \& Harper, 2016b).

\section{Defectiveness/Shame}

This schema refers to the belief that one is internally flawed, and that if others get close, they will realise this and withdraw from the relationship (e.g., "I feel that I am not loveable"). This feeling of being flawed and inadequate often leads to a strong sense of shame.

\section{Dependence/Incompetence}

This schema refers to the belief that one is not capable of handling day-to-day responsibilities competently and independently (e.g. "My judgment cannot be relied upon in everyday situations"). Generally, parents did not encourage these children to act independently and develop confidence in their ability to take care of themselves.

\section{Enmeshment/Undeveloped Self}

This schema refers to a pattern in which you experience too much emotional involvement with others - usually parents or romantic partners (e.g. "My parents and I tend to be over involved in each other's problems). This schema is often brought on by parents who are so controlling, abusive, or so overprotective that the child is discouraged from developing a separate sense of self.

\section{Emotional Inhibition}

This schema refers to the belief that you must suppress spontaneous emotions and impulses, (e.g. "I control myself so much that people think I am unemotional"). 
Psychotic experiences were measured using the Community Assessment of Psychic Experiences (CAPE; Stefanis et al., 2002). The CAPE is a 42 item self-report questionnaire which captures both positive (20 items) and negative (14 items) psychotic symptomology in conjunction with items relating to depressive ( 8 items) symptoms. Within the current study, only the 20 positive items were selected as these have been found to be more strongly linked with EMS (Sundag et al., 2016c. The CAPE items lie on a two-dimensional scale. The first dimension captures the frequency of symptoms on a 4-point Likert scale ranging from $1=$ "Never" to 4= "Nearly always", however for computing purposes the scale was recoded to $0=$ "Never" to 3= "Nearly always". The second dimension corresponds to the first and assesses the degree of distress associated with each endorsed experience. Responses range from $1=$ "Not distressed" to 4= "Very distressed". Dimension two is contingent upon a positive endorsement in dimension one, therefore, distress items are not requested if the symptoms are not endorsed initially. As such, a $0=$ "Not occur" category was retrospectively coded against the distress items which corresponded to the non-endorsement of symptoms from the frequency dimension. "Example items from the positive scale include; "Do you ever feel as if you are being persecuted in some way?", "Do you ever feel as if the thoughts in your head are not your own?", "Do you ever hear voices when you are alone?". A total score was then computed by summing all twenty frequencies and twenty distress items with scores ranging from 0 to 140. This generated a continuous measure, which encapsulates both frequency and distress elements with higher scores indicating greater combined frequency and distress. This method of conceptualising the data has been substantiated by recent studies, which provide evidence for the co-existence of positive psychotic symptoms alongside associated distress within the general population (Wigman et al., 2017). 


\section{Analytic Plan}

Direct effects ( $c^{`}$ paths) from the adverse life experience (ACE) to psychotic experiences were estimated. Second, the mediating variables (EMS) were introduced into the model and the direct effects between the ACE variables to mediators ( $a$ paths) and the mediators to the dependent variable (CAPE) ( $b$ paths) were estimated while controlling for the EMS variables (c`paths). Indirect effects were calculated using the product of two standardized paths linking the predictors (ACE) to the dependent variables (CAPE) through the EMS mediators (e.g. $a_{1}$ $\left.\mathrm{X} b_{1}\right)$. All covariates were included in the analysis and the model was specified and estimated in MPLUS 8 software (Muthén \& Muthén, 2017) using robust maximum likelihood (MLR) estimator.

\section{Results}

The mean age of the sample was 36 years $(\mathrm{SD}=11.6)$ and females were over-represented $(n=211,69.9 \%)$. The majority of participants reported living within an urban environment $(n=218,72.3 \%)$ and recorded their familial occupational classification as either professional $(n=52,17.2 \%)$ or skilled $(n=49,16.2 \%)$. Participants indicated Class B drugs were the most consumed drug, followed by Class A, then C. Descriptive statistics for all variables of interest are shown in Tables 1 and 2.

Standardised regression coefficients for the direct and mediated effects are presented in Tables 3 and Table 4 respectively.

\section{ACEs to EMS}

The observed results showed significant relationships between the relationship with parent variable and defectiveness $(\beta=0.279,95 \% \mathrm{CI}=0.404,0.154, p<0.001)$. Emotional abuse was statistically associated with defectiveness $(\beta=0.226,95 \% \mathrm{CI}=0.050,0.403, p=0.012)$, dependency $(\beta=0.249,95 \% \mathrm{CI}=0.046,0.452, p=0.016)$ and enmeshment $(\beta=0.287$, $95 \% \mathrm{CI}=0.095,0.479, p=0.003)$. The estimates for family environment on emotional 
inhibition were negative but statistically significant $(\beta=-0.107,95 \% \mathrm{CI}=-0.180,-0.034, p$ $=0.004)$ whilst the estimate from neglect to the CAPE was positive and significant $(\beta=0.134$, $95 \% \mathrm{CI}=0.019,0.250, p=0.023)$. Sexual abuse showed significant positive relationships with defectiveness $(\beta=0.124,95 \% \mathrm{CI}=0.008,0.241, p=0.013)$, dependency $(\beta=0.235$, $95 \% \mathrm{CI}=0.084,0.386, p<0.001)$, and enmeshment $(\beta=0.180,95 \% \mathrm{CI}=0.032,0.329, p<$ 0.001). However, a negative but significant relationship was observed for sexual abuse and emotional inhibition $(\beta=-0.056,95 \% \mathrm{CI}=-0.101,-0.011, p=0.014)$.

\section{EMS to PEs}

The observed results between the four mediators and CAPE scores showed positive and significant associations between defectiveness $(\beta=0.165,95 \% \mathrm{CI}=0.035,0.296, p=0.013)$, dependency $(\beta=0.332,95 \% \mathrm{CI}=0.191,0.473, p<0.001)$, and enmeshment $(\beta=0.219$, $95 \% \mathrm{CI}=0.110,0.329, p<0.001)$. The relationship between emotional inhibition and CAPE scores were negative but significant $(\beta=-0.160,95 \% \mathrm{CI}=-0.277,-0.043, p<0.05)$. The standardised regression coefficients are presented in Table 3.

\section{Mediated effects (ACE - EMS - PEs)}

The observed results from the mediated model showed defectiveness mediated the association between relationship with parents and CAPE scores $(\beta=0.046,95 \% \mathrm{CI}=0.087$, $0.005, p<0.05)$. Dependency mediated the relationship between emotional abuse $(\beta=0.083$, $95 \% \mathrm{CI}=0.010,0.155, p<0.05)$ and sexual abuse $(\beta=0.073,95 \% \mathrm{CI}=0.016,0.140, p<0.001)$ and CAPE scores. Finally, enmeshment mediated the relationship between emotional abuse $(\beta=0.063,95 \% \mathrm{CI}=0.008,0.118, p<0.05)$ and sexual abuse $(\beta=0.043,95 \% \mathrm{CI}=0.000,0.079$, $p<0.05)$. The standardised regression coefficients for the mediated effects are shown in Table 4. 
Table 1. Shows the economic breakdown of the sample and the frequency of drug use.

\begin{tabular}{|c|c|c|c|c|c|c|c|c|c|}
\hline \multicolumn{3}{|l|}{ Socioeconomic status } & \multirow[t]{2}{*}{ Items } & \multicolumn{2}{|c|}{ Class A } & \multicolumn{2}{|c|}{ Class B } & \multicolumn{2}{|c|}{ Class C } \\
\hline & $N=$ & $\%$ & & $\mathrm{n}=$ & $\%$ & $\mathrm{n}=$ & $\%$ & $\mathrm{n}=$ & $\%$ \\
\hline Unemployed & 9 & $(3.0)$ & Never & 197 & $(65.2)$ & 104 & $(34.4)$ & 254 & (84.1) \\
\hline Elementary & 26 & (8.6) & Once & 43 & $(14.2)$ & 64 & $(21.2)$ & 23 & (7.6) \\
\hline Process & 19 & $(6.3)$ & Occasionally & 49 & $(16.2)$ & 101 & $(33.4)$ & 19 & $(6.3)$ \\
\hline Sales & 32 & $(10.6)$ & Frequently & 6 & $(2.0)$ & 15 & $(5.0)$ & 4 & $(1.3)$ \\
\hline Personal service & 16 & $(5.3)$ & A lot & 7 & $(2.3)$ & 18 & $(6.0)$ & 2 & (.7) \\
\hline Skilled & 49 & $(16.2)$ & & & & & & & \\
\hline Admin & 35 & $(11.6)$ & & & & & & & \\
\hline Associate/professional & 35 & $(11.6)$ & & & & & & & \\
\hline Professional & 52 & $(17.2)$ & & & & & & & \\
\hline $\begin{array}{l}\text { Managers/senior } \\
\text { official }\end{array}$ & 28 & (9.3) & & & & & & & \\
\hline
\end{tabular}

Class A drug = Heroin (diamorphine), cocaine (including crack), methadone, ecstasy (MDMA), LSD, and magic mushrooms.

Class B drugs = Amphetamines, Barbiturates, Codeine, Cannabis, Cathinone's, and Synthetic Cannabinoids.

Class C = Benzodiazepines (tranquilisers), GHB/GBL, ketamine, anabolic steroids and benzylpiperazines (BZP). 
Table 2. Shows the summary statistics of all study variables.

\begin{tabular}{lccccc}
\hline Items & M & SD & Min - Max & Skew & Cronbach $\alpha$ \\
\hline Relation with Parents & 3.89 & $(1.89)$ & $0-8$ & .010 & - - \\
Witness IPV & 2.57 & $(2.36)$ & $0-12$ & $1.127^{*}$ & - - \\
Physical Abuse & 1.17 & $(1.33)$ & $0-8$ & $1.465 *$ & - - \\
Emotional Abuse & 1.24 & $(1.09)$ & $0-4$ & $.376 *$ & - - \\
Neglect & 2.12 & $(1.52)$ & $0-8$ & $1.553 *$ & - - \\
Family Environment & .89 & $(.91)$ & $0-3$ & $.779 *$ & - - \\
Sexual Abuse & .76 & $(1.3)$ & $0-4$ & $1.590 *$ & - - \\
Defectiveness & 1.39 & $(1.40)$ & $0-5$ & $.944 *$ & .93 \\
Dependency & .64 & $(.90)$ & $0-5$ & $2.011 *$ & .86 \\
Enmeshment & .55 & $(.81)$ & $0-5$ & $1.945 *$ & .79 \\
Emotional inhibition & 1.25 & $(.1 .26)$ & $0-5$ & $.995^{*}$ & .91 \\
CAPE composite & 23.28 & $(18.93)$ & $0-140$ & $1.139 *$ & .88 \\
\hline
\end{tabular}

Note: ${ }^{*}=$ Estimates of skew were statistically significant $(p<.05)$ 
Table 3. Regression Coefficients for Child Maltreatment, Schema and PE Variables

\begin{tabular}{|c|c|c|c|c|c|}
\hline & $\begin{array}{l}\text { Defectiveness } \\
\beta \text { (S.E) } 95 \% \mathrm{Cl}\end{array}$ & $\begin{array}{l}\text { Dependency } \\
\beta \text { (S.E) } 95 \% \mathrm{Cl}\end{array}$ & $\begin{array}{l}\text { Enmeshment } \\
\beta \text { (S.E) } 95 \% \mathrm{Cl}\end{array}$ & $\begin{array}{l}\text { Emotional Inhibition } \\
\qquad \beta \text { (S.E) } 95 \% \mathrm{Cl}\end{array}$ & $\begin{array}{c}\text { CAPE } \\
\beta(\text { S.E) } 95 \% \mathrm{Cl}\end{array}$ \\
\hline $\mathrm{X} 1$ & $\begin{array}{c}0.279(.06) \\
0.404,0.154\end{array}$ & $\begin{array}{c}-0.058(.06) \\
-0.181,0.065\end{array}$ & $\begin{array}{c}0.050(.06) \\
-0.076,0.175\end{array}$ & $\begin{array}{c}-0.030(.05) \\
-0.135,0.074\end{array}$ & $\begin{array}{c}-0.023(.05) \\
-0.125,0.079\end{array}$ \\
\hline $\mathrm{X} 2$ & $\begin{array}{c}0.024(.06) \\
-0.095,0.143\end{array}$ & $\begin{array}{c}0.059(.07) \\
-0.081,0.198\end{array}$ & $\begin{array}{c}0.074(.07) \\
-0.073,0.222\end{array}$ & $\begin{array}{c}-0.107(.03) \\
-0.180,-0.034\end{array}$ & $\begin{array}{c}0.050(.05) \\
-0.055,0.155\end{array}$ \\
\hline X3 & $\begin{array}{c}-0.129(.07) \\
-0.277,0.020\end{array}$ & $\begin{array}{c}-0.135(.07) \\
-0.276,0.006\end{array}$ & $\begin{array}{c}-0.114(.07) \\
-0.267,0.040\end{array}$ & $\begin{array}{c}0.026(.05) \\
-0.074,0.125\end{array}$ & $\begin{array}{c}0.096(.07) \\
-0.051,0.242\end{array}$ \\
\hline X4 & $\begin{array}{c}0.065(.07) \\
-0.084,0.214\end{array}$ & $\begin{array}{c}-0.049(.06) \\
-0.181,0.083\end{array}$ & $\begin{array}{c}-0.135(.08) \\
-0.291,0.021\end{array}$ & $\begin{array}{c}-0.086(.04) \\
-0.180,0.008\end{array}$ & $\begin{array}{c}0.082(.20) \\
-0.072,0.237\end{array}$ \\
\hline X5 & $\begin{array}{c}0.226(.09) \\
0.050,0.403\end{array}$ & $\begin{array}{c}0.249(.10) \\
0.046,0.452\end{array}$ & $\begin{array}{c}0.287(.09) \\
0.095,0.479\end{array}$ & $\begin{array}{c}0.044(.07) \\
-0.093,0.182\end{array}$ & $\begin{array}{c}-0.169(.09) \\
-0.354,0.016\end{array}$ \\
\hline X6 & $\begin{array}{c}-0.049(.08) \\
-0.212,0.114\end{array}$ & $\begin{array}{c}-0.016(.07) \\
-0.161,0.129\end{array}$ & $\begin{array}{c}-0.037(.08) \\
-0.212,0.138\end{array}$ & $\begin{array}{c}0.032(.04) \\
-0.056,0.121\end{array}$ & $\begin{array}{c}0.134(.05) \\
0.019,0.250\end{array}$ \\
\hline$x 7$ & $\begin{array}{c}0.124(.05) \\
0.008,0.241\end{array}$ & $\begin{array}{c}0.235(.07) \\
0.084,0.386\end{array}$ & $\begin{array}{c}0.180(.07) \\
0.032,0.329\end{array}$ & $\begin{array}{c}-0.056(.02) \\
-0.101,-0.011\end{array}$ & $\begin{array}{c}0.071(.05) \\
-0.031,0.174\end{array}$ \\
\hline \multicolumn{2}{|c|}{ Defectiveness } & -- & -- & -- & $\begin{array}{c}0.165(.07) \\
0.035,0.296\end{array}$ \\
\hline \multicolumn{2}{|c|}{ Dependency } & -- & -- & -- & $\begin{array}{c}0.332(.07) \\
0.191,0.473\end{array}$ \\
\hline \multicolumn{2}{|c|}{ Enmeshment } & -- & - - & -- & $\begin{array}{c}0.219(.05) \\
0.110,0.329\end{array}$ \\
\hline \multicolumn{2}{|c|}{ Emotional Inhibition } & -- & - - & - - & $\begin{array}{c}-0.160(.06) \\
-0.277,-0.043\end{array}$ \\
\hline
\end{tabular}

$\beta=$ Standardised beta coefficient, $(\mathrm{S} . \mathrm{E})=$ Standard error, $95 \% \mathrm{Cl}=95 \%$ Confidence Intervals. Model adjusted for age, gender, urbanicity, ethnicity, SES and drug categories (A, B, and C).

$\mathrm{X} 1=$ Relationship with Parents

$\mathrm{X} 2$ = Family Environment

$\mathrm{X} 3=$ Witness to Violence at home

$\mathrm{X} 4=$ Physical Abuse

$\mathrm{X} 5=$ Emotional Abuse

$\mathrm{X} 6=$ Neglect

$X 7=$ Sexual Abuse

CAPE $=$ Psychotic experiences 
Table 4. Shows Mediated effects defined as the product of two standardised paths linking $X$ to $Y$ through the mediators (e.g. $a_{1} b_{1}$ ).

\begin{tabular}{llcc}
\hline From Item & \multicolumn{1}{c}{ Via } & $\beta(\mathrm{S} . \mathrm{E}) 95 \% \mathrm{Cl}, \mathrm{P}$ value & To Item \\
\hline Relationship with parents & Defectiveness & $0.046(.02) 0.087,0.005^{*}$ & $\mathrm{PE}$ \\
Emotional abuse & Dependency & $0.083(.03) 0.010,0.155^{*}$ & $\mathrm{PE}$ \\
Emotional abuse & Enmeshment & $0.063(.02) 0.008,0.118^{*}$ & $\mathrm{PE}$ \\
Sexual abuse & Dependency & $0.078(.03) 0.016,0.140 *$ & $\mathrm{PE}$ \\
Sexual abuse & Enmeshment & $0.040(.02) 0.000,0.079 *$ & $\mathrm{PE}$ \\
\hline
\end{tabular}

$\beta=$ Standardised beta coefficient, $(\mathrm{S} . \mathrm{E})=$ Standard error, $95 \% \mathrm{Cl}=95 \%$ Confidence intervals, ${ }^{*}=<0.05, * *=<0.001$. Model adjusted for age, gender, urbanicity, ethnicity, SES and drug categories (A, B, and C).

$\mathrm{PE}=$ Psychotic experiences.

\section{Discussion}

The present study is the first to evaluate if early maladaptive schemas (EMS) uniquely mediate the relationship between early childhood trauma and psychotic experiences (PE) and associated distress within a general population sample. Results indicated that EMS are differentially related to various forms of childhood maltreatment, and specificity effects revealed that particular schemas mediated the maltreatment and PE relationship. Taken together, our findings suggest that the specific schemas that develop following adverse childhood events may, at least in part, contribute to the development of psychotic symptomology.

Both emotional and sexual abuse were positively associated with dependency and enmeshment schemas, which are components of the autonomy and performance domain. However, the estimates for emotional abuse on dependency and enmeshment were higher in magnitude than sexual abuse across all EMS mediators, which is consistent with other research (Arata, Langhinrichsen-Rohling, Bowers, \& O'Farrill-Swails, 2005; Edwards, Holden, Felitti, \& Anda, 2003), and may indicate that emotional abuse has a more profound 
psychological impact on individuals than other forms of abuse (Cecil, Viding, Fearon, Glaser, $\&$ McCrory, 2017). It is currently unknown to what extent emotional abuse without sexual abuse, child sexual abuse only, and sexual abuse with other abuse types may increase the likelihood of long-term adjustment problems (Turner, Taillieu, Cheung, \& Afifi, 2017). Some argue, that whilst emotional abuse is an important form of abuse in its own right, it may actually underpin other forms of abuse, or perhaps even magnify their effects (Edwards et al., 2003; Hart, Brassard, Binggeli, \& Davidson, 2002). Indeed, while it is debated whether childhood sexual abuse could be perpetrated in the absence of emotional abuse (Bernstein et al., 1994; Goldsmith \& Freyd, 2005), the stronger associations between emotional abuse and EMS items than sexual abuse and EMS items may be accounted for by the wide matrix of negative experiences that constitute emotional abuse. Such acts include restricting a child's movements, ridicule, threats, intimidation, rejection and other nonphysical forms of hostile treatment. These experiences may limit the opportunity for children to avail of emotional and social support necessary for coping with co-occurring forms of maltreatment (Runyan, MayChahal, Hassan, \& Ramiro, 2002; Turner et al., 2017). Another plausible line of reasoning may be, where there is a persistent or a chronic undercurrent of emotional abuse types, particularly during developmental milestones, children may perceive the cognitive impact of emotional abuse more detrimental than acute or isolated experiences of sexual abuse.

The second hypothesis was confirmed. We hypothesised a significant relationship between EMS and PEs would exist. This finding aligns with existing literature that found negative cognitive schemas are characteristic of psychosis and are often underpinned by low self-esteem, worry, depression or neuroticism that may not only increase the risk of developing psychosis, but may also function as maintaining factors (Hanssen, Krabbendam, De Graaf, Vollebergh, \& Van OS, 2005; Krabbendam et al., 2002, 2005; Krabbendam \& van Os, 2005). 
The final hypothesis was also confirmed. Results showed that specific EMS domains may act as intermediary pathways by which adverse childhood experiences are linked to psychotic experiences. Given the interrelatedness of abusive experiences and contextual overlap of the EMS subscales; when interpreted together, the mediation model intuitively offers a conceptual theory. When serious forms of abuse take place, it is likely to convey the message that the child's core self is a disappointment because he or she has not lived up to expectations, or is simply not worthy of love and attention (Cecil et al., 2017b). This notion aligns with research from cognitive models of psychosis used within clinical and non-clinical samples (Appiah-Kusi et al., 2017). Evidence suggests, childhood maltreatment may create an enduring cognitive vulnerability, characterized by negative schematic models of the self and the world that facilitates appraisal biases and low self-esteem, particularly if criticism stems directly from family members (Barrowclough et al., 2003; Garety, Bebbington, Fowler, Freeman, \& Kuipers, 2007; Garety et al., 2001b; Tiernan, Tracey, \& Shannon, 2014). Indeed, results showed that having a poor parental relationship was positively associated with defectiveness/shame, which is part of the disconnection and rejection domain. This aligns with Young et al., (2003e), that this domain typically encompasses families that are detached or cold, rejecting, unpredictable, or abusive. Such cognitive schemas surrounding vulnerability have in turn been linked to an inherent predisposition to psychotic symptomology including hallucinations and delusions (Garety et al., 2001c; Kraan et al., 2017b).

Furthermore, coercive techniques and psychological abuse often take place in abusive familial environments, and feelings of dependency and enmeshment with one or both parents may develop in such contexts. Exposure to such experiences are also likely to impinge upon a child's ability to observe, mimic and adopt their parent's behaviour as they withdraw as a means of self-preservation, or are drawn closer to an overprotective parent, especially if that 
parent is experiencing, or is a survivor of, abuse themselves (Sanderson, 2006). Indeed, individuals who exhibit schemas from Domain II: impaired autonomy and performance, typically have a family origin that is enmeshed, and overprotective which can undermine the child's confidence for performing competently outside the family environment (Young et al., 2003f). Over time, this may translate not only to personal feelings of inadequacy, but also to developmental delays in acquiring skills which has been shown to precede the onset of psychosis (Boyda \& McFeeters, 2015b).

\section{Implications / Future research}

The conclusions drawn from the current study should be considered in light of several limitations. First, concerns have been raised regarding the use of mediation analysis on crosssectional data, as by definition, mediation analysis examines mechanisms over time (Cole \& Maxwell, 2003; Maxwell, Cole, \& Mitchell, 2011). Therefore, whilst the proposed model offers a plausible, evidence-based theoretical framework from which future analyses may be developed, it is also possible that psychotic illness cultivates certain maladaptive schemas rather than schemas leading to development of psychosis itself. Future research would benefit from a longitudinal approach to establish a better understanding of temporal sequencing and stability of the observed relationships over the course of the lifespan. Moreover, replication studies are needed to help determine the robustness of the specificity effects across various samples and to establish whether the remaining EMS may also demonstrate specificity effects with ACE and PE's. Second, it could be argued that the participants' recall of childhood may be affected by any psychiatric presentations, attenuated or otherwise. However, recent literature suggests that retrospective self-reports of childhood adversity by patients with psychosis can be considered reliable (Fisher et al., 2009). There is also the possibility the online nature of this study excluded those who do not have access to mobile devices or 
internet access. Finally, the study lacked diagnostic heterogeneity in the comparison group, and the absence of a healthy control group, something future studies should address.

\section{Clinical implications}

The current findings affirm the hypothesised role of childhood maltreatment in the formation of EMS which in turn, may contribute to the development and perpetuation of psychotic symptomology. Since psychotic experiences predicts clinical psychotic disorder particularly in the presence of persistent distress, early intervention in individuals with a history of maltreatment may reduce the likelihood of transitory developmental expression of clinically relevant psychosis (van Os, Linscott, Myin-Germeys, Delespaul, \& Krabbendam, 2009). From a practitioner's perspective, these findings offer credence to cognitive theories of psychopathology (e.g., (Beck, 1991) and support the validity of EMS identification and adjustment among clients with psychotic symptomology.

With this in mind, not all pathways were significant. This would indicate that certain forms of childhood maltreatment might be more likely to result in an elevation of particular EMS and moreover, that distinct types of EMS may be more pertinent in relation to psychotic symptomology. This knowledge is likely to have direct clinical utility for case conceptualisation and ensuing treatment strategies since evidence suggests, when psychotic patients are better able to conceptualise the precipitating factors and begin to attribute current symptoms to distal life events, this can promote positive therapeutic benefits (Klapheck, Nordmeyer, Cronjäger, Naber, \& Bock, 2012). Proponents of the emerging hearing voice movement suggest that such experiences should not be thought to be automatically indicative of clinical pathology. Accordingly, mainstream therapeutic approaches which promote the complete elimination of these experiences may not constitute a feasible objective in every instance. Instead, improvements in subjective well-being may also be achieved through 
greater acceptance and normalisation of such overt responses to experienced adversity

(Corstens, Longden, McCarthy-Jones, Waddingham, \& Thomas, 2014). In essence, research

which helps to trace the origins and pathways to current experiences may ease this process, helping individuals to frame the salience of these experiences in the context of their own interpersonal narrative.

\section{Conclusion}

Our findings suggest tentatively, that a putative cognitive pathway between early childhood maltreatment and later psychosis risk could be contingent on the development of early maladaptive schemas. Indeed, some argue that exposure to early trauma may not be sufficient to trigger the onset of psychosis (Misiak et al., 2017). Therefore, our findings support the need for systematic investigation of not only the occurrence of child maltreatment, but the potential presentation of EMSs since both may synergistically combine to index risk for later onset of a psychotic disorder. In addition, the findings support the use of psychological interventions that target the modification of specific maladaptive schemas in those who have experienced maltreatment as a child. Research has found the combination of schema guided interventions with cognitive strategies showed analogous to superior effects than cognitive therapy as the sole treatment in improving negative self-schemas and interpersonal selfconcepts (Sundag et al., 2016). This may not only beneficial for tailoring treatment during therapeutic practice but also for advancing our theoretical understanding of the aetiology of psychotic states and symptomology. 


\section{Acknowledgements}

NA.

\section{Conflicts of interest}

On behalf of all authors, the corresponding author states that there is no conflict of interest.

\section{Ethics}

This study was approved by University of Wolverhampton ethics committee and have therefore been performed in accordance with the ethical standards laid down in the 1964 Declaration of Helsinki and its later amendments 


\section{References}

Abajobir, A. A., Kisely, S., Scott, J. G., Williams, G., Clavarino, A., Strathearn, L., \& Najman, J. M. (2017). Childhood Maltreatment and Young Adulthood Hallucinations, Delusional Experiences, and Psychosis: A Longitudinal Study. Schizophrenia Bulletin, 43(5), 1045-1055. https://doi.org/10.1093/schbul/sbw175

Appiah-Kusi, E., Fisher, H. L., Petros, N., Wilson, R., Mondelli, V., Garety, P. A., ... Bhattacharyya, S. (2017). Do cognitive schema mediate the association between childhood trauma and being at ultra-high risk for psychosis? Journal of Psychiatric Research, 88, 89-96. https://doi.org/10.1016/j.jpsychires.2017.01.003

Arata, C. M., Langhinrichsen-Rohling, J., Bowers, D., \& O’Farrill-Swails, L. (2005). Single versus multitype maltreatment: An examination of the long-term effects of child abuse. Journal of Aggression, Maltreatment \& Trauma, 11(4), 29-52.

Banyard, V. L., Williams, L. M., \& Siegel, J. A. (2001). The long-term mental health consequences of child sexual abuse: An exploratory study of the impact of multiple traumas in a sample of women. Journal of Traumatic Stress, 14(4), 697-715.

Barrowclough, C., Tarrier, N., Humphreys, L., Ward, J., Gregg, L., \& Andrews, B. (2003). Self-esteem in schizophrenia: relationships between self-evaluation, family attitudes, and symptomatology. Journal of Abnormal Psychology, 112(1), 92-99.

Beck, A. T. (1991). Cognitive therapy and the emotional disorders. London: Penguin.

Bernstein, D. P., Fink, L., Handelsman, L., Foote, J., Lovejoy, M., Wenzel, K., ... Ruggiero, J. (1994). Initial reliability and validity of a new retrospective measure of child abuse and neglect. The American Journal of Psychiatry, 151(8), 1132-1136. https://doi.org/10.1176/ajp.151.8.1132

Bhavsar, V., Boydell, J., McGuire, P., Harris, V., Hotopf, M., Hatch, S. L., ... Morgan, C. (2017).

Childhood abuse and psychotic experiences - evidence for mediation by adulthood adverse 
life events. Epidemiology and Psychiatric Sciences, 1-10.

https://doi.org/10.1017/S2045796017000518

Bonoldi, I., Simeone, E., Rocchetti, M., Codjoe, L., Rossi, G., Gambi, F., ... Fusar-Poli, P. (2013).

Prevalence of self-reported childhood abuse in psychosis: A meta-analysis of retrospective studies. Psychiatry Research, 210(1), 8-15. https://doi.org/10.1016/j.psychres.2013.05.003

Bortolon, C., Capdevielle, D., Boulenger, J.-P., Gely-Nargeot, M.-C., \& Raffard, S. (2013). Early maladaptive schemas predict positive symptomatology in schizophrenia: A cross-sectional study. Psychiatry Research, 209(3), 361-366.

https://doi.org/10.1016/j.psychres.2013.03.018

Boyda, D., \& McFeeters, D. (2015). Childhood Maltreatment and Social Functioning in Adults with Sub-Clinical Psychosis. Psychiatry Research, 226(1), 376-382.

https://doi.org/10.1016/j.psychres.2015.01.023

Cecil, C. A. M., Viding, E., Fearon, P., Glaser, D., \& McCrory, E. J. (2017). Disentangling the mental health impact of childhood abuse and neglect. Child Abuse \& Neglect, 63(Supplement C), 106-119. https://doi.org/10.1016/j.chiabu.2016.11.024

Christoffersen, M. N., Armour, C., Lasgaard, M., Andersen, T. E., \& Elklit, A. (2013). The prevalence of four types of childhood maltreatment in Denmark. Clinical Practice and Epidemiology in Mental Health: CP \& EMH, 9, 149-156.

Cole, D. A., \& Maxwell, S. E. (2003). Testing mediational models with longitudinal data: questions and tips in the use of structural equation modeling. Journal of Abnormal Psychology, 112(4), 558-577. https://doi.org/10.1037/0021-843X.112.4.558

Cormier, A., Jourda, B., Laros, C., Walburg, V., \& Callahan, S. (2011). [Influence between early maladaptive schemas and depression]. L'Encephale, 37(4), 293-298.

https://doi.org/10.1016/j.encep.2011.01.001 
Corstens, D., Longden, E., McCarthy-Jones, S., Waddingham, R., \& Thomas, N. (2014). Emerging Perspectives From the Hearing Voices Movement: Implications for Research and Practice. Schizophrenia Bulletin, 4O(Suppl_4), S285-S294. https://doi.org/10.1093/schbul/sbu007

Cutajar, M., Mullen PE, Ogloff JP, Thomas SD, Wells DL, \& Spataro J. (2010). Schizophrenia and other psychotic disorders in a cohort of sexually abused children. Archives of General Psychiatry, 67(11), 1114-1119. https://doi.org/10.1001/archgenpsychiatry.2010.147

Dias, A., Sales, L., Mooren, T., Mota-Cardoso, R., \& Kleber, R. (2017). Child maltreatment, revictimization and Post-Traumatic Stress Disorder among adults in a community sample. International Journal of Clinical and Health Psychology, 17(2), 97-106. https://doi.org/10.1016/j.ijchp.2017.03.003

Dutra, L., Callahan, K., Forman, E., Mendelsohn, M., \& Herman, J. (2008). Core schemas and suicidality in a chronically traumatized population. The Journal of Nervous and Mental Disease, 196(1), 71-74. https://doi.org/10.1097/NMD.0b013e31815fa4c1

Edwards, V. J., Holden, G. W., Felitti, V. J., \& Anda, R. F. (2003). Relationship between multiple forms of childhood maltreatment and adult mental health in community respondents: results from the adverse childhood experiences study. American Journal of Psychiatry, 160(8), 14531460.

Fisher, H., Morgan, C., Dazzan, P., Craig, T. K., Morgan, K., Hutchinson, G., ... Fearon, P. (2009). Gender differences in the association between childhood abuse and psychosis. The British Journal of Psychiatry, 194(4), 319-325. https://doi.org/10.1192/bjp.bp.107.047985

Flink, N., Lehto, S. M., Koivumaa-Honkanen, H., Viinamäki, H., Ruusunen, A., Valkonen-Korhonen, M., \& Honkalampi, K. (2017). Early maladaptive schemas and suicidal ideation in depressed patients. The European Journal of Psychiatry, 31(3), 87-92. https://doi.org/10.1016/j.ejpsy.2017.07.001 
Galletly, C., Van Hooff, M., \& McFarlane, A. (2011). Psychotic symptoms in young adults exposed to childhood trauma-A 20year follow-up study. Schizophrenia Research, 127(1-3), 76-82. https://doi.org/10.1016/j.schres.2010.12.010

Garety, P., Bebbington, P., Fowler, D., Freeman, D., \& Kuipers, E. (2007). Implications for neurobiological research of cognitive models of psychosis: a theoretical paper. Psychological Medicine, 37(10), 1377-1391. https://doi.org/10.1017/S003329170700013X

Garety, P., Kuipers, E., Fowler, D., Freeman, D., \& Bebbington, P. (2001). A cognitive model of the positive symptoms of psychosis. Psychological Medicine, 31(2), 189-195.

Gilbert, R., Widom, C. S., Browne, K., Fergusson, D., Webb, E., \& Janson, S. (2009). Burden and consequences of child maltreatment in high-income countries. The Lancet, 373(9657), 6881. https://doi.org/10.1016/S0140-6736(08)61706-7

Goldsmith, R., \& Freyd, J. (2005). Awareness for Emotional Abuse (Vol. 5). https://doi.org/10.1300/J135v05n01_04

Hanssen, M., Krabbendam, L., De Graaf, R., Vollebergh, W., \& Van OS, J. I. M. (2005). Role of Distress in Delusion Formation. The British Journal of Psychiatry, 187(48), s55-s58. https://doi.org/10.1192/bjp.187.48.s55

Hart, S. ., Brassard, M. ., Binggeli, N. ., \& Davidson, H. . (2002). Psychological maltreatment. In J. E. . Myers, L. Berliner, J. Briere, C. . Hendricks, C. Jenny, \& T. . Reid (Eds.), The APSAC handbook on child maltreatment (Vol. 2nd, pp. 79-103). Thousand Oaks, CA: Sage Publications.

Hawke, L. D., \& Provencher, M. D. (2011). Schema theory and schema therapy in mood and anxiety disorders: A review. Journal of Cognitive Psychotherapy, 25(4), 257-276.

Kaymaz, N., Drukker, M., Lieb, R., Wittchen, H.-U., Werbeloff, N., Weiser, M., ... van Os, J. (2012). Do subthreshold psychotic experiences predict clinical outcomes in unselected non-helpseeking population-based samples? A systematic review and meta-analysis, enriched with new results. Psychological Medicine, 42(11), 2239-2253.

https://doi.org/10.1017/\$0033291711002911 
Klapheck, K., Nordmeyer, S., Cronjäger, H., Naber, D., \& Bock, T. (2012). Subjective experience and meaning of psychoses: the German Subjective Sense in Psychosis Questionnaire (SUSE). Psychological Medicine, 42(1), 61-71. https://doi.org/10.1017/S0033291711001103

Kraan, T. C., Ising, H. K., Fokkema, M., Velthorst, E., van den Berg, D. P. G., Kerkhoven, M., ... van der Gaag, M. (2017). The effect of childhood adversity on 4-year outcome in individuals at ultra high risk for psychosis in the Dutch Early Detection Intervention Evaluation (EDIE-NL) Trial. Psychiatry Research, 247, 55-62. https://doi.org/10.1016/j.psychres.2016.11.014

Krabbendam, L., Janssen, I., Bak, M., Bijl, R. V., de Graaf, R., \& van Os, J. (2002). Neuroticism and low self-esteem as risk factors for psychosis. Social Psychiatry and Psychiatric Epidemiology, 37(1), 1-6.

Krabbendam, L., Myin-Germeys, I., Hanssen, M., Graaf, R., Vollebergh, W., Bak, M., \& Os, J. (2005). Development of depressed mood predicts onset of psychotic disorder in individuals who report hallucinatory experiences. British Journal of Clinical Psychology, 44(1), 113-125. https://doi.org/10.1348/014466504X19767

Krabbendam, L., \& van Os, J. (2005). Affective processes in the onset and persistence of psychosis. European Archives of Psychiatry and Clinical Neuroscience, 255(3), 185-189. https://doi.org/10.1007/s00406-005-0586-6

Krause, E. D., Mendelson, T., \& Lynch, T. R. (2003). Childhood emotional invalidation and adult psychological distress: the mediating role of emotional inhibition. Child Abuse \& Neglect, 27(2), 199-213. https://doi.org/10.1016/S0145-2134(02)00536-7

Linscott, R. J., \& van Os, J. (2013). An updated and conservative systematic review and meta-analysis of epidemiological evidence on psychotic experiences in children and adults: on the pathway from proneness to persistence to dimensional expression across mental disorders. Psychological Medicine, 43(6), 1133-1149. https://doi.org/10.1017/S0033291712001626 
Manly, J. T., Cicchetti, D., \& Barnett, D. (1994). The impact of subtype, frequency, chronicity, and severity of child maltreatment on social competence and behavior problems. Development and Psychopathology, 6(01), 121-143. https://doi.org/10.1017/S0954579400005915

Maxwell, S. E., Cole, D. A., \& Mitchell, M. A. (2011). Bias in Cross-Sectional Analyses of Longitudinal Mediation: Partial and Complete Mediation Under an Autoregressive Model. Multivariate Behavioral Research, 46(5), 816-841. https://doi.org/10.1080/00273171.2011.606716

McGrath, J. J., McLaughlin, K. A., Saha, S., Aguilar-Gaxiola, S., Al-Hamzawi, A., Alonso, J., ... others. (2017). The association between childhood adversities and subsequent first onset of psychotic experiences: a cross-national analysis of 23998 respondents from 17 countries. Psychological Medicine, 47(7), 1230-1245.

Misiak, B., Krefft, M., Bielawski, T., Moustafa, A. A., Sąsiadek, M. M., \& Frydecka, D. (2017). Toward a unified theory of childhood trauma and psychosis: A comprehensive review of epidemiological, clinical, neuropsychological and biological findings. Neuroscience \& Biobehavioral Reviews, 75, 393-406. https://doi.org/10.1016/j.neubiorev.2017.02.015

Molendijk, M. L., Hoek, H. W., Brewerton, T. D., \& Elzinga, B. M. (2017). Childhood maltreatment and eating disorder pathology: a systematic review and dose-response meta-analysis. Psychological Medicine, 47(8), 1402-1416. https://doi.org/10.1017/S0033291716003561

Mørkved, N., Endsjø, M., Winje, D., Johnsen, E., Dovran, A., Arefjord, K., ... others. (2017). Childhood trauma in schizophrenia spectrum disorder as compared to other mental health disorders. Psychosis, 9(1), 48-56.

Muthén, L. K., \& Muthén, B. O. (2017). Mplus User's Guide (Eighth Edition). Los Angeles, CA: Muthen \& Muthen.

Rafaeli, E., Bernstein, D. P., \& Young, J. (2010). Schema Therapy: Distinctive Features (1 edition). Routledge. 
Reininghaus, U., Priebe, S., \& Bentall, R. P. (2012). Testing the Psychopathology of Psychosis: Evidence for a General Psychosis Dimension. Schizophrenia Bulletin, 39(4), 884-895. https://doi.org/10.1093/schbul/sbr182

Runyan, D., May-Chahal, C., Hassan, F., \& Ramiro, L. S. (2002). Child abuse and neglect by parents and other caregivers. In E. G. Krug \& Weltgesundheitsorganisation (Eds.), World report on violence and health (p. 346). Geneva: World Health Organisation.

Sanderson, C. (2006). Counselling Adult Survivors of Child Sexual Abuse (3 edition). London; Philadelphia: Jessica Kingsley.

Sommer, I. E. C., Daalman, K., Rietkerk, T., Diederen, K. M., Bakker, S., Wijkstra, J., \& Boks, M. P. M. (2010). Healthy individuals with auditory verbal hallucinations; who are they? Psychiatric assessments of a selected sample of 103 subjects. Schizophrenia Bulletin, 36(3), 633-641. https://doi.org/10.1093/schbul/sbn130

Stefanis, N. C., Hanssen, M., Smirnis, N. K., Avramopoulos, D. A., Evdokimidis, I. K., Stefanis, C. ., ... others. (2002). Evidence that three dimensions of psychosis have a distribution in the general population. Psychological Medicine, 32(02), 347-358.

Sundag, J., Ascone, L., de Matos Marques, A., Moritz, S., \& Lincoln, T. M. (2016). Elucidating the role of Early Maladaptive Schemas for psychotic symptomatology. Psychiatry Research, 238, 5359. https://doi.org/10.1016/j.psychres.2016.02.008

Taylor, C. D. J., \& Harper, S. F. (2016). Early maladaptive schema, social functioning and distress in psychosis: A preliminary investigation. Clinical Psychologist, 21(2), 142. https://doi.org/10.1111/cp.12082

Thimm, J. C. (2013). Early maladaptive schemas and interpersonal problems: A circumplex analysis of the YSQ-SF. International Journal of Psychology and Psychological Therapy, 13(1), 113-124.

Tiernan, B., Tracey, R., \& Shannon, C. (2014). Paranoia and self-concepts in psychosis: a systematic review of the literature. Psychiatry Research, 216(3), 303-313. https://doi.org/10.1016/j.psychres.2014.02.003 
Turner, S., Taillieu, T., Cheung, K., \& Afifi, T. O. (2017). The relationship between childhood sexual abuse and mental health outcomes among males: Results from a nationally representative United States sample. Child Abuse \& Neglect, 66(Supplement C), 64-72. https://doi.org/10.1016/j.chiabu.2017.01.018

Vallejos, M., Cesoni, O. M., Farinola, R., Bertone, M. S., \& Prokopez, C. R. (2017). Adverse Childhood Experiences among Men with Schizophrenia. Psychiatric Quarterly, 88(4), 665-673. https://doi.org/10.1007/s11126-016-9487-2

van Os, J., \& Linscott, R. J. (2012). Introduction: The Extended Psychosis Phenotype-Relationship With Schizophrenia and With Ultrahigh Risk Status for Psychosis. Schizophrenia Bulletin, 38(2), 227-230. https://doi.org/10.1093/schbul/sbr188

Van Os, J., Linscott, R. J., Myin-Germeys, I., Delespaul, P., \& Krabbendam, L. (2009). A systematic review and meta-analysis of the psychosis continuum: evidence for a psychosis pronenesspersistence-impairment model of psychotic disorder. Psychological Medicine, 39(2), 179195. https://doi.org/10.1017/S0033291708003814

Varese, F., Smeets, F., Drukker, M., Lieverse, R., Lataster, T., Viechtbauer, W., ... Bentall, R. P. (2012). Childhood Adversities Increase the Risk of Psychosis: A Meta-analysis of Patient-Control, Prospective- and Cross-sectional Cohort Studies. Schizophrenia Bulletin, 38(4), 661-671. https://doi.org/10.1093/schbul/sbs050

Whitfield, C. L., Dube, S. R., Felitti, V. J., \& Anda, R. F. (2005). Adverse childhood experiences and hallucinations. Child Abuse \& Neglect, 29(7), 797-810. https://doi.org/10.1016/j.chiabu.2005.01.004

Wigman, J. T. W., Wardenaar, K. J., Wanders, R. B. K., Booij, S. H., Jeronimus, B. F., van der Krieke, L., ... de Jonge, P. (2017). Dimensional and discrete variations on the psychosis continuum in a Dutch crowd-sourcing population sample. European Psychiatry, 42, 55-62. https://doi.org/10.1016/j.eurpsy.2016.11.014 
Wingenfeld, K., Schäfer, I., Terfehr, K., Grabski, H., Driessen, M., Grabe, H., ... Spitzer, C. (2011). [The reliable, valid and economic assessment of early traumatization: first psychometric characteristics of the German version of the Adverse Childhood Experiences Questionnaire (ACE)]. Psychotherapie, Psychosomatik, Medizinische Psychologie, 61(1), e10-14. https://doi.org/10.1055/s-0030-1263161

Young, J. E., Klosko, J. S., \& Weishaar, M. E. (2003). Schema therapy: A practitioner's guide. Guilford Press. Retrieved from https://books.google.co.uk/books?hl=en\&lr=\&id=vScjGGgJEZgC\&oi=fnd\&pg=PA1\&dq=Young ,+Klosko+and+Weishaar+(2003)\&ots=hS-YbDGe_I\&sig=5wAiltRA5vJHWfFSyLQxYy0X3VA

Zammit, S., Kounali, D., Cannon, M., David, A. S., Gunnell, D., Heron, J., ... Lewis, G. (2013). Psychotic experiences and psychotic disorders at age 18 in relation to psychotic experiences at age 12 in a longitudinal population-based cohort study. The American Journal of Psychiatry, 170(7), 742-750. https://doi.org/10.1176/appi.ajp.2013.12060768 